\title{
Interfacial Characteristic of as-Deformed SiCp-Reinforced Magnesium Matrix Composite
}

\author{
Kun Kun Deng $\cdot$ Jian Chao Li $\cdot$ Jian Feng Fan $\cdot$ Xiao Jun Wang $\cdot$ Kun Wu $\cdot$ Bing She Xu
}

Received: 6 May 2014/Revised: 12 August 2014/Published online: 6 September 2014

(C) The Chinese Society for Metals and Springer-Verlag Berlin Heidelberg 2014

\begin{abstract}
The (submicron + micron) SiCp-reinforced magnesium matrix composite was fabricated by stir casting. After the application of forging and extrusion, the interface between $\mathrm{SiCp}$ and $\mathrm{Mg}$ in the composite was investigated by transmission electron microscopy. Results show that the interfacial characterization was different at the interfaces of micron-SiCp/Mg and submicron-SiCp/Mg. While most interfaces between micron-SiCp and $\mathrm{Mg}$ were clean, the precipitated $\mathrm{Mg}_{17} \mathrm{Al}_{12}$ phase as well as dispersedly distributed nano- $\mathrm{MgO}$ particles was observed at some interfaces. Unlike the interface between micron-SiCp and $\mathrm{Mg}$, no interfacial reaction product was found at the interface between submicron-SiCp and $\mathrm{Mg}$ in the present study. Besides, the specific orientation relationships were found at the interfaces between submicron$\mathrm{SiCp}$ and $\mathrm{Mg}$, which was thought to have developed during hot deformation process. At the fracture surface of the composite, the microcracks were found at the interface between micron-SiCp and $\mathrm{Mg}$, while the interfacial bonding between submicron-SiCp and $\mathrm{Mg}$ was very well.
\end{abstract}

KEY WORDS: Magnesium matrix composite; SiC particles; Interfaces; TEM

\section{Introduction}

Compared to monolithic alloys, magnesium matrix composites exhibit better specific strength, high wear, and creep resistance as well as low coefficient of thermal

Available online at http://link.springer.com/journal/40195

K. K. Deng · J. C. Li

College of Materials Science and Engineering,

Taiyuan University of Technology, Taiyuan 030024, China

K. K. Deng $(\varangle)$ · J. F. Fan · B. S. Xu

Key laboratory of interface science and engineering in advanced materials, Ministry of Education, Taiyuan University of

Technology, Taiyuan 030024, China

e-mail: jamsdk@163.com

X. J. Wang $(\bowtie) \cdot K$. Wu

School of Materials Science and Engineering,

Harbin Institute of Technology, Harbin 150001, China

e-mail: xjwang@hit.edu.cn expansion, so they have received much attention as important structural materials in aerospace, automobile, and transport industries, etc. [1-4]. According to the type of reinforcements, the magnesium matrix composites can be divided into fiber [5,6], whisker [1, 7], and particle [2, 8-11]-reinforced magnesium matrix composites. Among them, particle-reinforced magnesium matrix composites fabricated by stir casting possess extensive application prospect for low processing cost, high production rate, and high performance $[12,13]$.

Generally speaking, the addition of particles can not only refine grain size by promoting nucleation and inhibiting the migration of grain boundaries, but also promote load transfer [14-16]. So, the interface between particle and matrix plays a key role in the development of highperformance composites [17]. It is thought that the characterization of interface may influence the crack development and load transfer effect during deformation, thus affecting the mechanical properties of composites [17]. The nature of interface depends on a variety of factors: process 

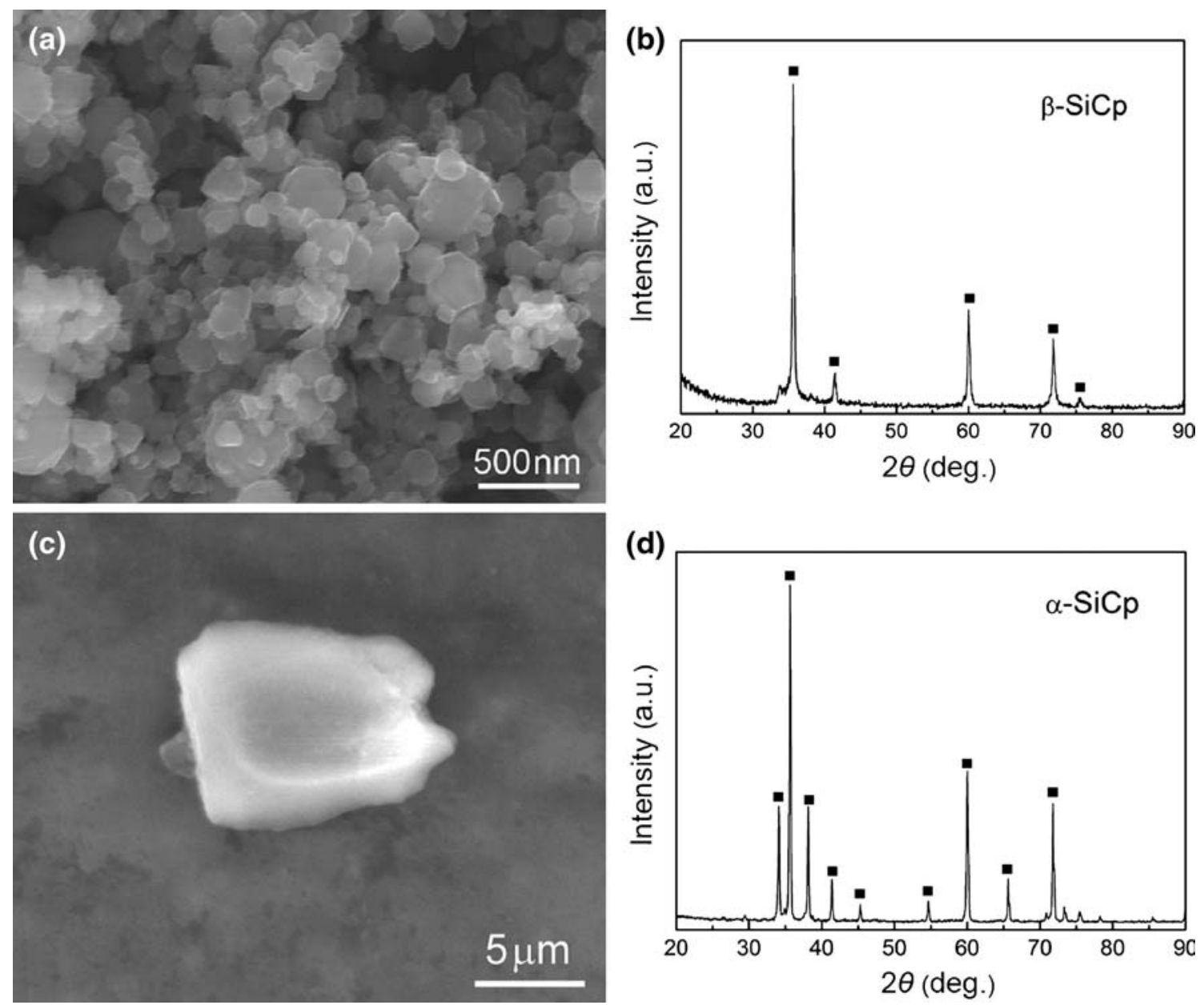

Fig. 1 SEM micrographs and XRD patterns of SiCp: a SEM micrograph of $0.2 \mu \mathrm{m} \mathrm{SiCp} \mathrm{[24];} \mathrm{b} \mathrm{XRD} \mathrm{pattern} \mathrm{of} 0.2 \mu \mathrm{m}$ SiCp; c SEM micrograph of $10 \mu \mathrm{m} \mathrm{SiCp} \mathrm{[25];} \mathrm{d} \mathrm{XRD} \mathrm{pattern} \mathrm{of} 10 \mu \mathrm{m} \mathrm{SiCp} \mathrm{[25]}$

parameters [10], matrix composition [18], the composition and the nature of the surface of the reinforcement [19], the thermal treatment conditions applied to the composites [1, 20], etc. About the effect of above factors on the interface bonding, much work has been conducted. Luo et al. [21] reported that the interfacial reaction products were found in SiCp-reinforced AZ91 composite, but there are no reaction products in SiCp-reinforced pure Mg composite. Laurent et al. [22] found that the occurrence of reaction products depended on fabrication temperature. Wang et al. [14] reported that both the interfacial reaction products and precipitate-free interfaces were found in the as-cast $\mathrm{SiCp} /$ AZ91 composites fabricated at $720{ }^{\circ} \mathrm{C}$ through stir casting.

So far, the research on interfacial characterization between particle and $\mathrm{Mg}$ matrix mainly focuses on the ascast magnesium matrix composite. Some orientation relationships are observed between SiC-precipitates and SiC$\mathrm{Mg}$ [23]. To refine grain size, improve particle distribution and enhance the mechanical properties, and the hot deformation has been applied on the magnesium matrix composite [2]. However, the interface characteristics of the as-deformed $\mathrm{SiCp}$-reinforced magnesium matrix composite have not been well understood at present.

In this work, the magnesium alloy reinforced by 1 vol\% $0.2 \mu \mathrm{m} \mathrm{SiCp}$ and 9 vol\% $10 \mu \mathrm{m} \mathrm{SiCp}$ fabricated through stir casting was deformed by the combination of forging and extrusion process. The aim is to reveal the interfacial characterization in the as-deformed SiCp-reinforced magnesium matrix composite.

\section{Experimental}

Magnesium alloy with the composition of $\mathrm{Mg}-9.3 \mathrm{Al}-$ $0.7 \mathrm{Zn}-0.25 \mathrm{Mn}$ was selected as matrix alloy. Two sizes of $\mathrm{SiC}$ particles $(0.2$ and $10 \mu \mathrm{m})$ were selected as reinforcement. Figure 1 shows the SEM micrographs and XRD patterns of 0.2 and $10 \mu \mathrm{m} \mathrm{SiCp}$. It demonstrates that both the surface of 0.2 and $10 \mu \mathrm{m} \mathrm{SiCp}$ were clean, as shown in Fig. 1a, c. By XRD analysis, the $0.2 \mu \mathrm{m} \mathrm{SiCp}$ belongs to $\beta$ - 

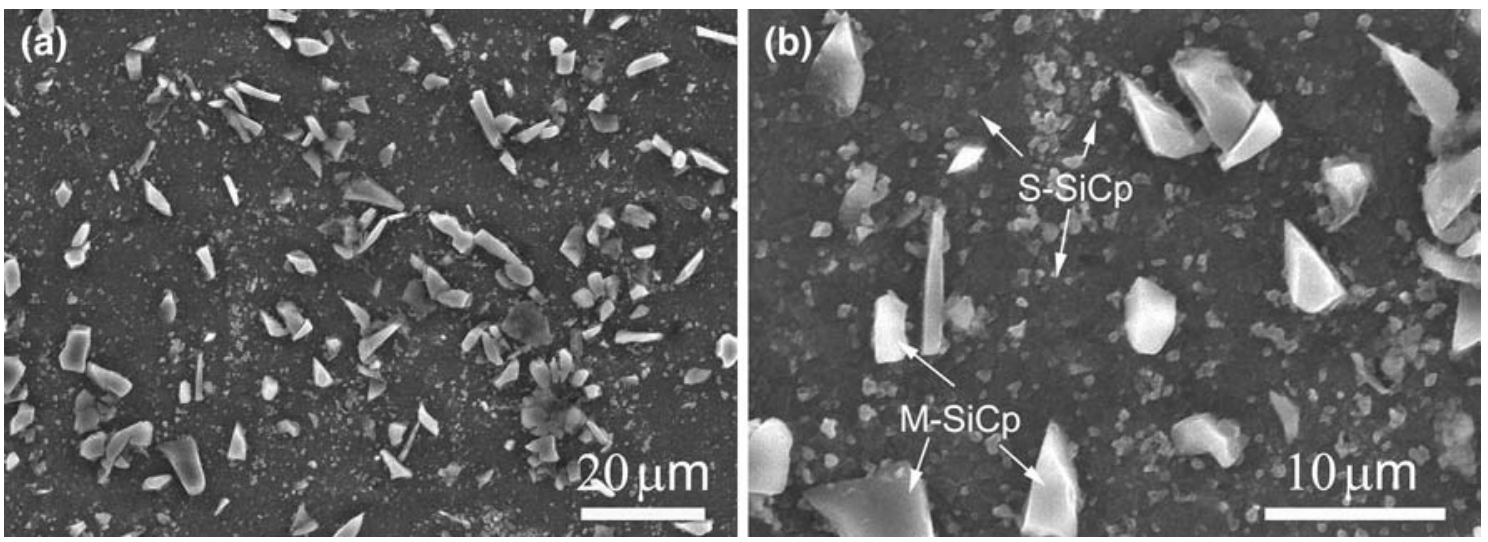

Fig. 2 SEM images of SiCp-reinforced magnesium matrix composite after hot extrusion: a lower magnification; b higher magnification

SiCp (Fig. 1b) and $10 \mu \mathrm{m}$ SiCp belongs to $\alpha$-SiCp (Fig. 1d). No other phase could be detected in both the XRD patterns of 0.2 and $10 \mu \mathrm{m} \mathrm{SiCp}$, which correspond to the SEM micrographs of Fig. 1a, c, respectively.

In the present study, the $0.2 \mu \mathrm{m} \mathrm{SiCp}$ is denoted as "S$\mathrm{SiCp}$ " and the $10 \mu \mathrm{m} \mathrm{SiCp}$ is denoted as "M-SiCp." The whole volume fraction of $\mathrm{SiCp}$ is set as 10 vol\%. The $(1 \mathrm{vol} \% \mathrm{~S}-\mathrm{SiCp}+9$ vol\% $\mathrm{M}-\mathrm{SiCp})$ reinforced magnesium matrix composite was fabricated by stir casting. The detailed description of stir casting has been described in Ref. [16]. After solution treatment at $415{ }^{\circ} \mathrm{C}$ for $24 \mathrm{~h}$, the composite was forged at $420{ }^{\circ} \mathrm{C}$ with $50 \%$ reduction, and then subjected to extrusion at $370{ }^{\circ} \mathrm{C}$ with a ratio of $16: 1$ at a constant ram speed of $15 \mathrm{~mm} / \mathrm{s}$.

Microstructure observation was carried out by optical microscopy (OM), scanning electron microscopy (SEM), and transmission electron microscopy (TEM, Tecnai $\mathrm{G}^{2}$ F30). The specimens for OM were ground, polished, and then etched in acetic picral $(5 \mathrm{~mL}$ acetic acid $+6 \mathrm{~g}$ picric acid $+10 \mathrm{~mL} \mathrm{H}_{2} \mathrm{O}+100 \mathrm{~mL}$ ethanol $(95 \mathrm{vol} \%)$ ) to investigate the morphological characteristics of grains. The as-deformed composite was ground and polished to investigate the particle distribution by SEM. A foil with $50-\mu \mathrm{m}$ thickness was prepared by grinding and polishing. After being punched to 3-mm-diameter disks, the foil was ion-thinned by following parameters: voltage is $4.5 \mathrm{kV}$, current is $0.5 \mathrm{~mA}$, and angle of incidence is $7^{\circ}-15^{\circ}$. Then, the interface in the composites was examined by TEM.

\section{Results and Discussion}

\subsection{Microstructures}

Figure 2 shows the SEM images of SiCp-reinforced magnesium matrix composite after hot extrusion. It illustrates that the S-SiCp and M-SiCp were relatively uniformly distributed in the Mg matrix (Fig. 2a). Besides, no porosity was detected (Fig. 2b), and the interface between SiCp and $\mathrm{Mg}$ was very good by SEM observation, which might be attributed to the application of forging and extrusion process [16].

The morphology of M-SiCp and S-SiCp is shown in Fig. 3a, b, respectively. Stacking faults could be seen clearly in both of the M-SiCp and S-SiCp. Such faults are also found in a number of micron and submicron $\mathrm{SiC}$ particles. In the author's previous study, it had demonstrated that the micron-SiCp belongs to hexagonal structure, while the submicron-SiCp belongs to face-centered cubic structure [16].

\subsection{Interface between M-SiCp and Magnesium}

By the TEM observation of M-SiCp in Fig. 3a, the interface between $\mathrm{M}-\mathrm{SiCp}$ and $\mathrm{Mg}$ matrix was very clean, no interfacial reaction products (IRPs) were observed at the interface. Based on the authors' study, most interfaces between M-SiCp and Mg matrix are clean.

The precipitated phase could be found at the interfaces between $\mathrm{M}-\mathrm{SiCp}$ and $\mathrm{Mg}$ matrix, as shown in Fig. 4a. Figure $4 \mathrm{~b}$ shows the electron diffraction pattern of the secondary phase along $[1 \overline{13}]$ zone axis, which indicates that the precipitate phase is $\mathrm{Mg}_{17} \mathrm{Al}_{12}$. As described in Sect. 2, the composite was treated at $415{ }^{\circ} \mathrm{C}$ for $24 \mathrm{~h}$ in order to eliminate the influence of $\mathrm{Mg}_{17} \mathrm{Al}_{12}$. At the first deformation process, the forging temperature is $420{ }^{\circ} \mathrm{C}$ which is higher than the solution temperature. So the $\mathrm{Mg}_{17} \mathrm{Al}_{12}$ phase could not be precipitated at this process. However, the subsequent extrusion temperature is $370{ }^{\circ} \mathrm{C}$, which is within the precipitated temperature range of $\mathrm{Mg}_{17} \mathrm{Al}_{12}$. So unlike the results that were reported by Wang et al. [14] and Cai et al. [23], the $\mathrm{Mg}_{17} \mathrm{Al}_{12}$ at the interface of M-SiCp most likely precipitated during the hot extrusion process. In 

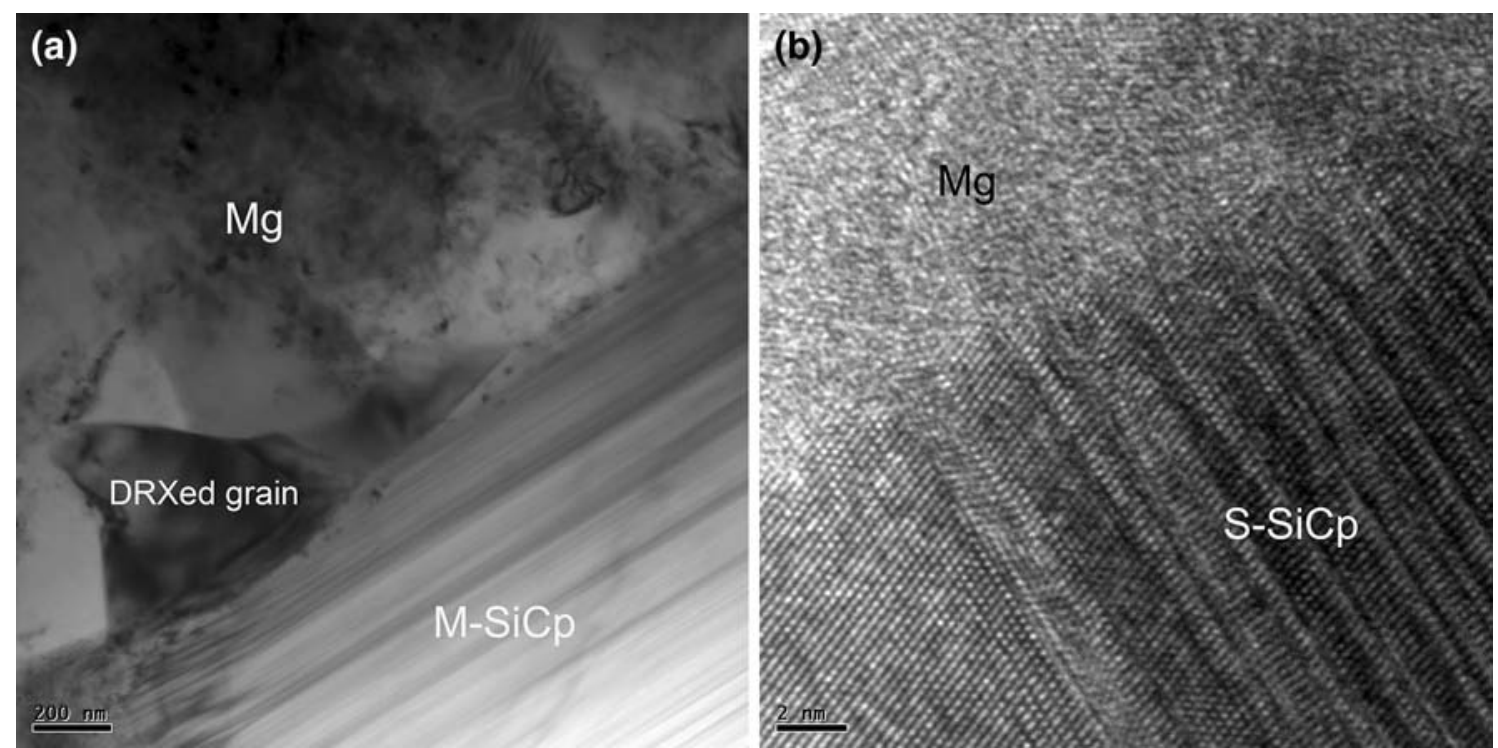

Fig. 3 Morphologies of M-SiCp by TEM a, S-SiCp by HREM $\mathbf{b}$ in the as-extruded composite
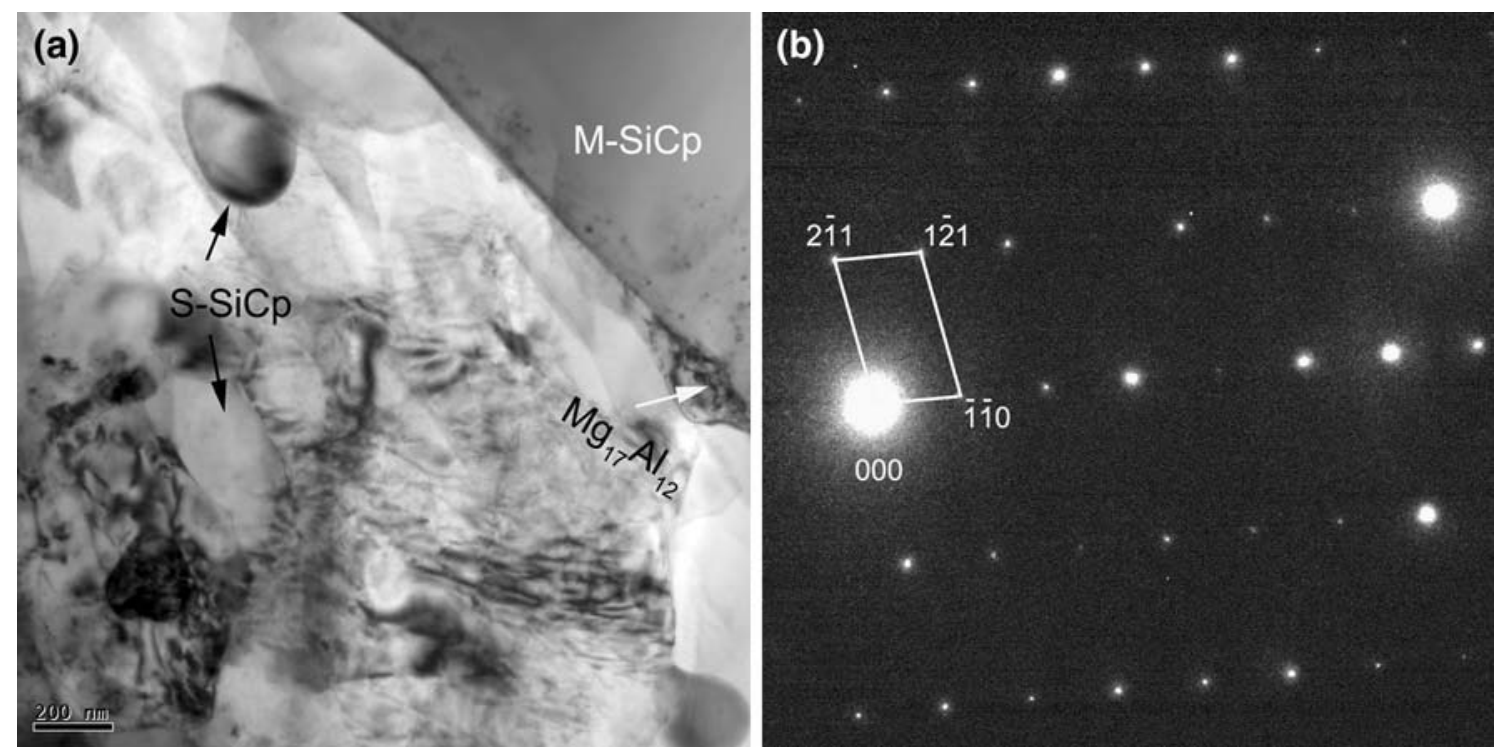

Fig. 4 TEM micrograph at the interface between M-SiCp and $\mathrm{Mg}$ a, electron diffraction pattern of secondary phase $\left(\mathrm{Mg}_{17} \mathrm{Al} \mathrm{l}_{12}\right)$ along $[1 \overline{13}]$ zone axis $\mathbf{b}$

fact, it has been illustrated by Zheng et al. [26] that the addition of $\mathrm{SiC}$ whisker can not only provide more nucleation sites but also enhance solute diffusion. So the $\mathrm{Mg}_{17} \mathrm{Al}_{12}$ precipitated preferentially at the interface between M-SiCp and Mg matrix.

A small amount of $\mathrm{Mg}_{17} \mathrm{Al}_{12}$ phase was also found at the area away from M-SiCp. The TEM morphology of secondary phase in this area is shown in Fig. 5a. It demonstrates that the secondary phase can be classified into two types according to the shape. One kinds of the phase had an angular shape. By electron diffraction pattern along [1 $\overline{13}]$ zone axis, this kind of phase was determined to be $\mathrm{S}-\mathrm{SiCp}$ with face-centered cubic structure. The other kinds of the phase had a circular shape. With the help of electron diffraction pattern along [113] zone axis, this kind of phase was determined to be $\mathrm{Mg}_{17} \mathrm{Al}_{12}$. Figure 5a also shows that the size of circular $\mathrm{Mg}_{17} \mathrm{Al}_{12}$ was smaller than that of angular S-SiCp. Even though the amount of precipitated $\mathrm{Mg}_{17} \mathrm{Al}_{12}$ was very little, it is thought to favor for the improvement of mechanical properties.

Three kind interfaces between $\mathrm{M}-\mathrm{SiCp}$ and $\mathrm{Mg}$ matrix are found by TEM observation in the present study: (1) 

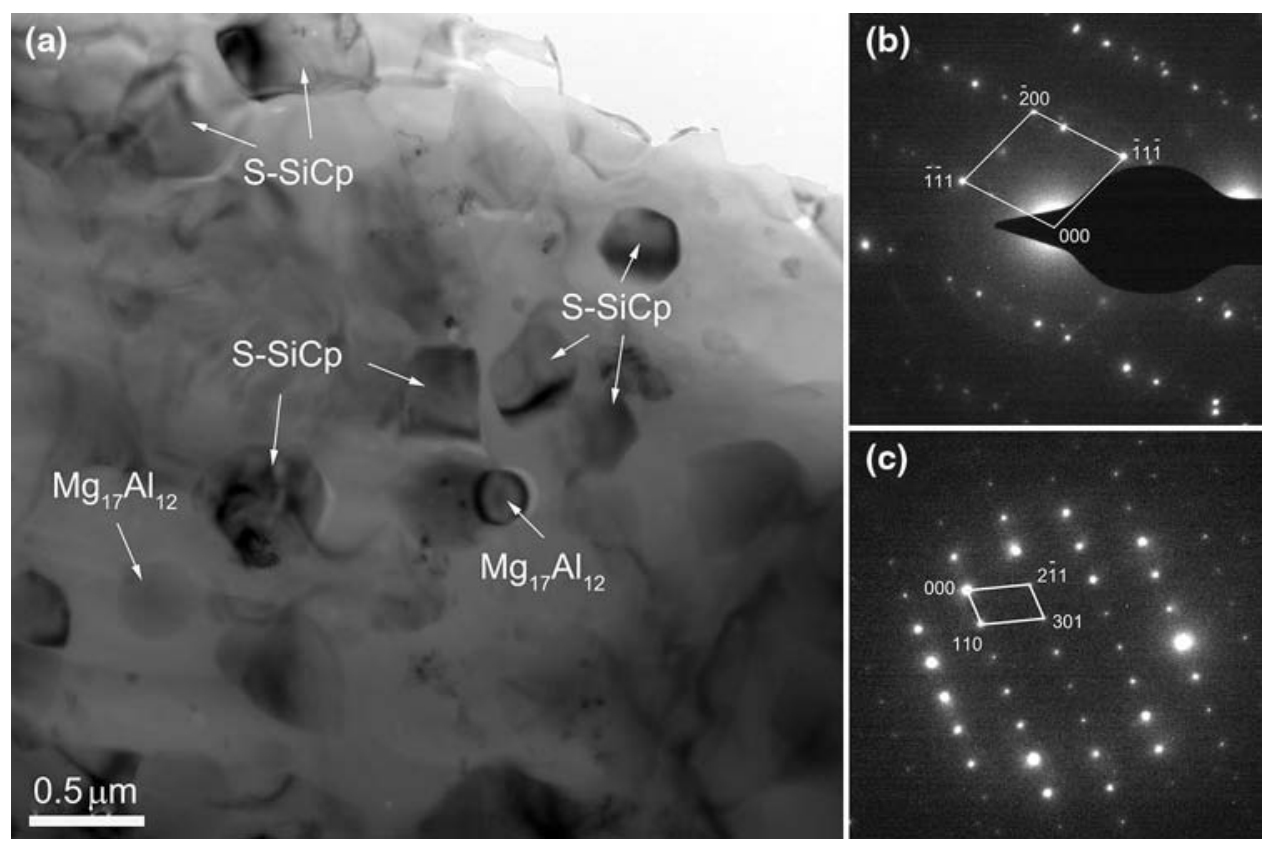

Fig. 5 TEM micrographs of the composite showing the morphology of secondary phases a, electron diffraction patterns of S-SiCp along [011] zone axis b, $\mathrm{Mg}_{17} \mathrm{Al}_{12}$ along [113] zone axis $\mathbf{c}$
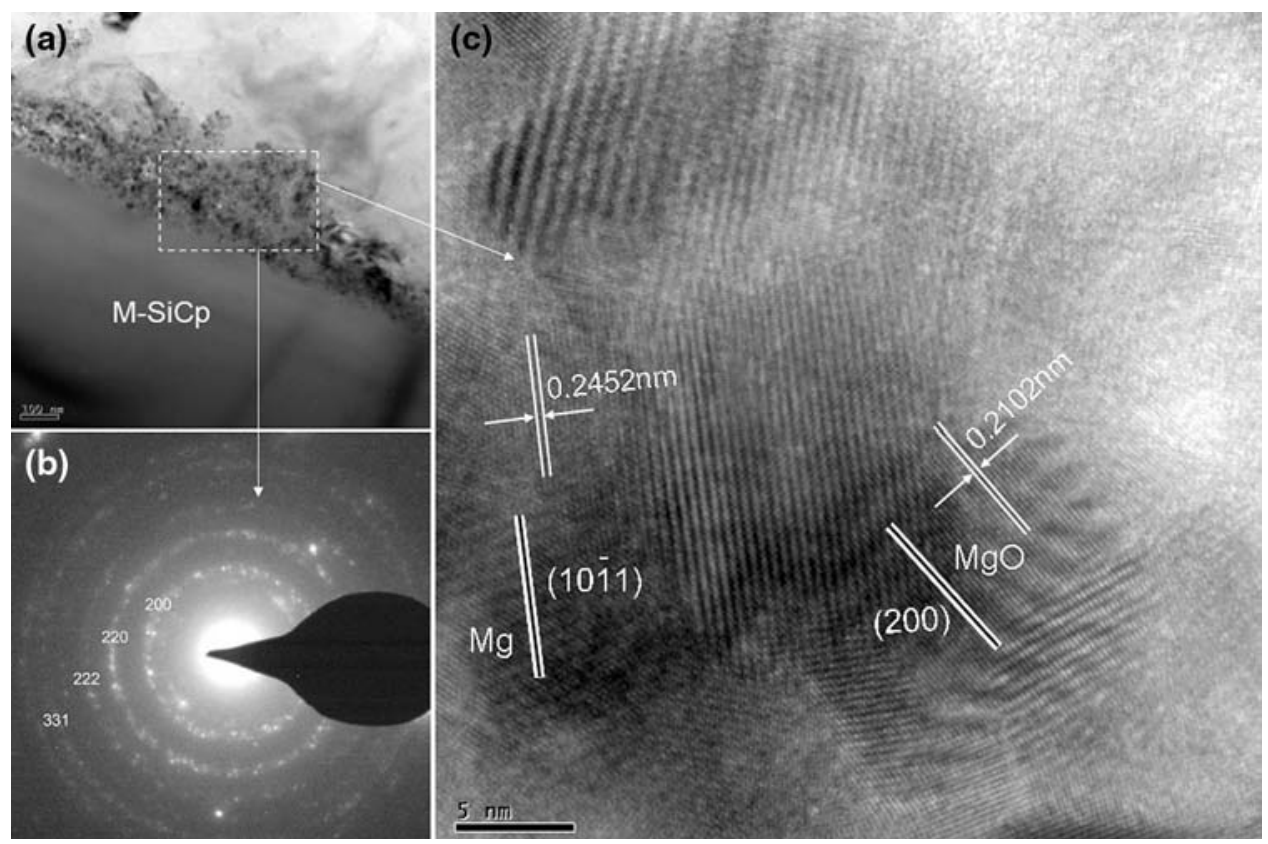

Fig. 6 Secondary phases at the interface between M-SiCp and Mg: a morphology of secondary phases; $\mathbf{b}$ selected area diffraction indicates that secondary phases are nano-MgO particles; c HREM image of nano-MgO particle

clean interface without IRPs; (2) interface with the existence of $\mathrm{Mg}_{17} \mathrm{Al}_{12}$ phase; and (3) interface with the dispersedly distributed nano-MgO particles. Figure 6 shows the third type interface between $\mathrm{M}-\mathrm{SiCp}$ and $\mathrm{Mg}$ matrix. Figure 6a shows that the nano-sized secondary phases were dispersedly distributed at the interface. By the selected area diffraction in Fig. $6 \mathrm{~b}$, it confirms that this kind of secondary phase is nano- $\mathrm{MgO}$ particles. Figure $6 \mathrm{c}$ shows the high resolution electron microscopy (HREM) image of the nano-MgO particle. It indicates that the interface bonding between nano- $\mathrm{MgO}$ and $\mathrm{Mg}$ was very good, and no defects were found at the interface. It is thought that the nano- $\mathrm{MgO}$ particles were formed during the fabrication process of the composite [14]. In the present study, the 


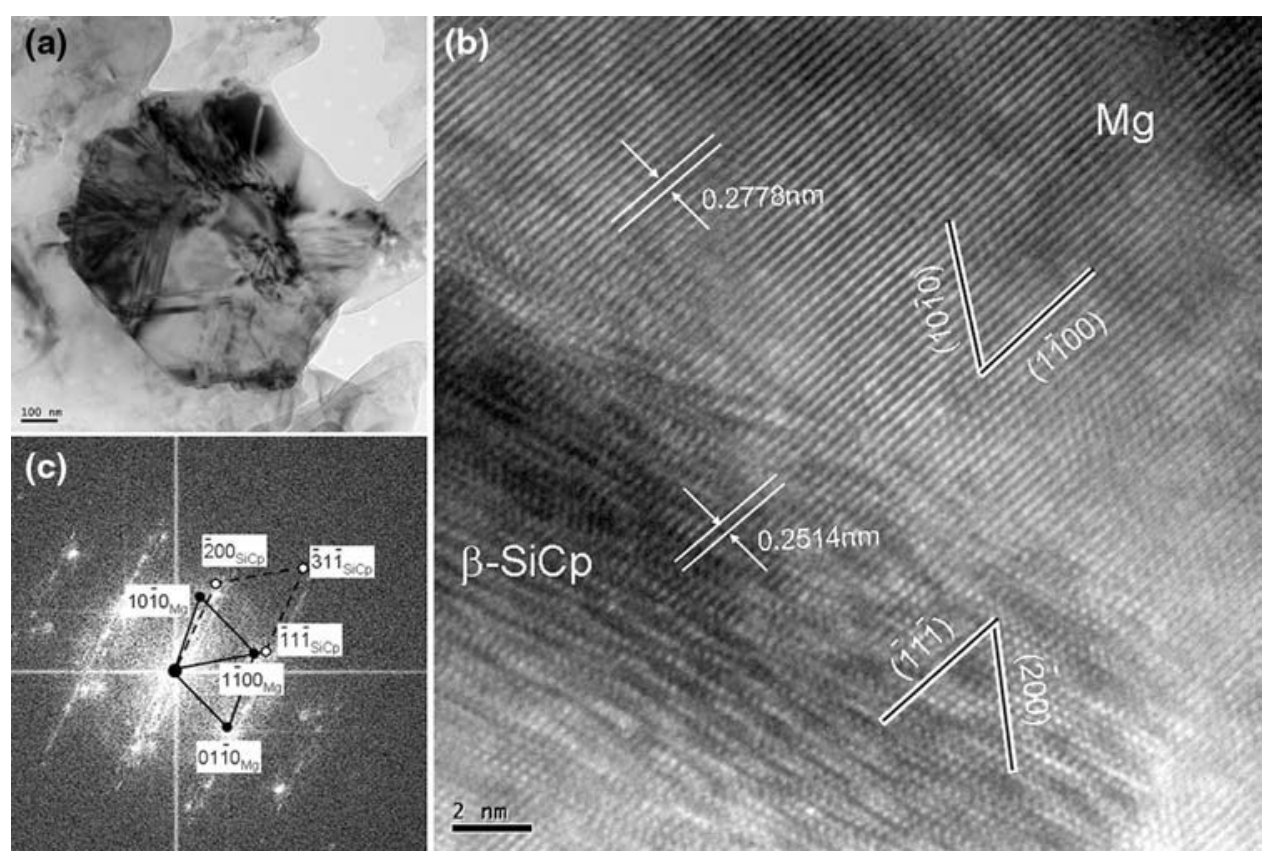

Fig. 7 TEM images of interface between S-SiCp and Mg: a TEM morphology of interface; b HREM image of interface; $\mathbf{c}$ filtration image of Fig. $7 b$

SiCp-reinforced magnesium matrix composite was fabricated by semi-solid stir casting technology. During this process, a small amount of the liquid surface might contact with $\mathrm{O}_{2}$, which would react with $\mathrm{Mg}$, thus the $\mathrm{MgO}$ particles could form and then were stirred into the material. On the other hand, the surface of M-SiC particles could adsorb a small amount of $\mathrm{O}_{2}$, which would react with $\mathrm{Mg}$ during the fabrication process, resulting in the formation of the $\mathrm{MgO}$ particles. However, the whole fabrication process was protected by the mixed gas of $\left(\mathrm{CO}_{2}+\mathrm{SF}_{6}\right)$, and the $\mathrm{SiCp}$ was preheated at $600{ }^{\circ} \mathrm{C}$ for $2 \mathrm{~h}$ before being added into $\mathrm{Mg}$, so the amount of $\mathrm{MgO}$ particles generated during the fabrication process is very small. The nano-sized $\mathrm{MgO}$ particles were also found in $\mathrm{SiCw} / \mathrm{Mg}$ composites by Zheng et al. [27], and it was thought to be beneficial to the improvement of mechanical properties. Only a little amount $\mathrm{MgO}$ particles exists in the present composite, so the effect of $\mathrm{MgO}$ on the mechanical properties is negligible.

\subsection{Interface between S-SiCp and Magnesium}

As mentioned in Sect. 3.2, the interfaces of both $\mathrm{M}-\mathrm{SiCp} /$ $\mathrm{Mg}$ and $\mathrm{S}-\mathrm{SiCp} / \mathrm{Mg}$ are very well by SEM observation. Unlike the interface between $\mathrm{M}-\mathrm{SiCp}$ and $\mathrm{Mg}$, the interface between $\mathrm{S}-\mathrm{SiCp}$ and $\mathrm{Mg}$ was very clean and no IRPs were found in the present study. Figures $3 b, 4$ and 5 show the TEM morphologies of S-SiC particles. It is revealed that the interface was sharp and clean and no voids could be found at the interface. Especially, the HREM image of Fig. $3 \mathrm{~b}$ demonstrates that the interface was clean and no interfacial reaction product existed. Besides, two kinds of orientation relationships at the interface between $\mathrm{S}-\mathrm{SiCp}$ and $\mathrm{Mg}$ were found by HREM. The TEM morphology of the first kind of interface is shown in Fig. 7a. It illustrates that the $\mathrm{S}-\mathrm{SiCp}$ and $\mathrm{Mg}$ connected directly at the interface. By the Fourier transform image of Fig. 7b, the diffraction pattern of interface could be obtained, as shown in Fig. 7c. By combining Fig. $7 \mathrm{~b}$ with $\mathrm{c}$, the orientation relationships at the interface can be described as follows:

$$
\begin{aligned}
& (\overline{1} 1 \overline{1})_{\mathrm{S}-\mathrm{SiCp}} / /(1 \overline{1} 00)_{\mathrm{Mg}} \\
& {[011]_{\mathrm{S}-\mathrm{SiCp}} / /[0001]_{\mathrm{Mg}} \text {. }}
\end{aligned}
$$

The second orientation relationship between $\mathrm{S}-\mathrm{SiCp}$ and $\mathrm{Mg}$ is shown in Fig. 8. Figure 8a shows the TEM morphology of the interface along the axis zone [011] of SSiCp. By the Fourier transform of Fig. 8b, the diffraction pattern of interface is shown in Fig. 8c. By combining Fig. $8 \mathrm{~b}$ with $\mathrm{c}$, the second orientation relationship at the interface can be described as follows:

$$
\begin{aligned}
& (\overline{2} 00)_{\mathrm{S}-\mathrm{SiCp}} / /(0 \overline{1} 12)_{\mathrm{Mg}} \\
& {[011]_{\mathrm{S}-\mathrm{SiCp}} / /[12 \overline{3} 1]_{\mathrm{Mg}}}
\end{aligned}
$$

From the above analysis, two kinds of different orientation relationships between $\mathrm{S}-\mathrm{SiCp}$ and $\mathrm{Mg}$ were observed in the as-extruded composite. For the $(\overline{1} 1 \overline{1})$ plane of SSiCp parallel to the (1100) plane of $\mathrm{Mg}$, the mismatch can be generated as follows: 

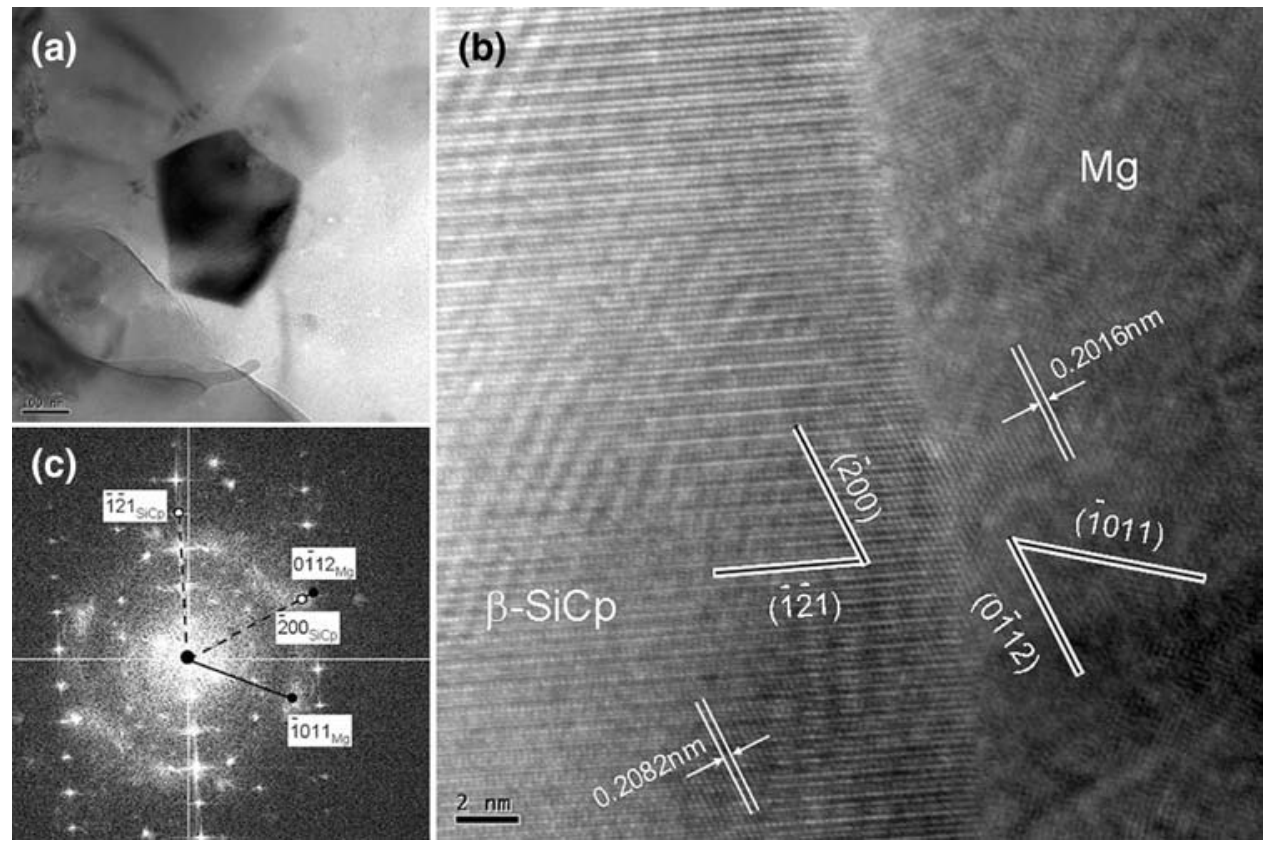

Fig. 8 The Second orientation relationship between S-SiCp and Mg: a TEM morphology of the interface along axis zone [011] of S-SiCp; b HREM image of interface; c filtration image of Fig. $8 \mathrm{~b}$
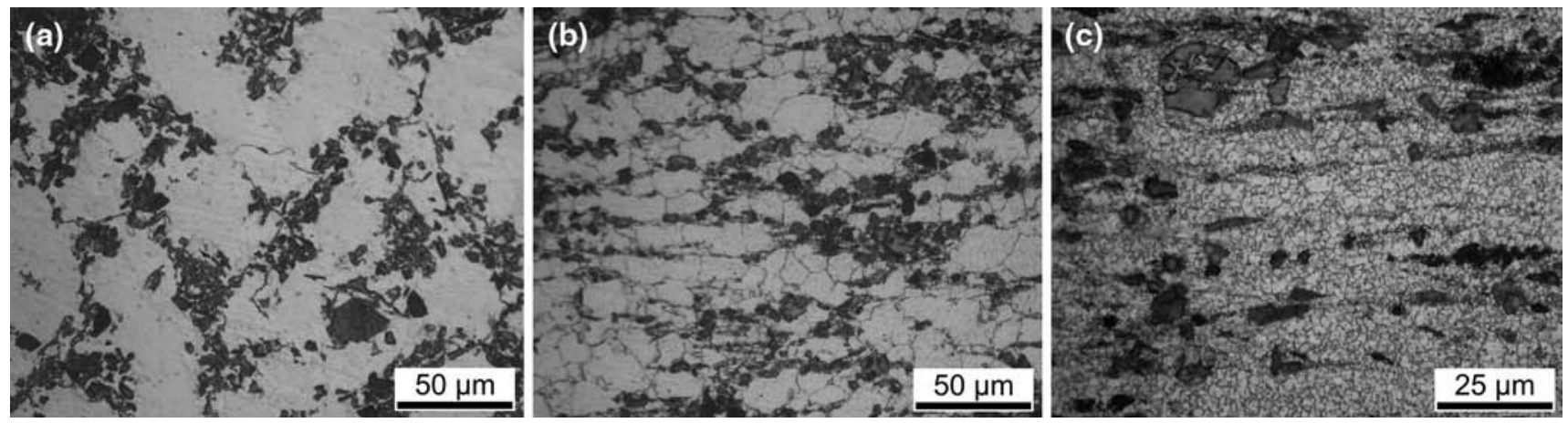

Fig. 9 Optical micrographs of as-cast $\mathbf{a}$, as-forged $\mathbf{b}$, as-extruded $\mathbf{c}$ SiCp-reinforced magnesium matrix composites

$$
\begin{aligned}
\delta & =\left(\mathrm{d}(1 \overline{1} 00)_{\mathrm{Mg}}-\mathrm{d}(0 \overline{1} 1 \overline{1})_{\mathrm{S}-\mathrm{SiCp}}\right) / \mathrm{d}(1 \overline{1} 00)_{\mathrm{Mg}} \times 100 \% \\
& =(0.2778-0.2514) / 0.2778 \times 100 \% \\
& =9.5 \% .
\end{aligned}
$$

For the orientation relationship of $(\overline{2} 00)_{\mathrm{S}-\mathrm{SiCp}} / /$ $(0 \overline{1} 12)_{\mathrm{Mg}}$, the mismatch generated is about $3.17 \%$. For the two kinds of interface, the lattice mismatch is small with little lattice misfit strain at the interface, and the two kinds of interface can be considered as a semi-coherent interface. It suggests a good interface bonding between $\mathrm{S}-\mathrm{SiCp}$ and Mg matrix.

The specific orientation relationships had been reported in the as-cast magnesium matrix composite [23, 28]. It was thought that the energy needed for nucleation and growth is lower if the matrix crystallized at certain orientation relationships between secondary phase and $\mathrm{Mg}$, which could result in low misfit stain and good interface bonding. As mentioned in Sect. 2, the composite was forged at $420{ }^{\circ} \mathrm{C}$, and then subjected to extrusion at $370{ }^{\circ} \mathrm{C}$. Figure 9 shows the optical micrographs of SiCp-reinforced magnesium matrix composite. In the as-cast composite, the grain size was very large, as shown in Fig. 9a. By the first forging process, the grain size was refined obviously, as shown in Fig. 9b. After the subsequent extrusion process, the average gain size was only $\sim 1.5 \mu \mathrm{m}$, as shown in Fig. 9c. Besides, the equiaxed grains were obtained after both forging and extrusion process. So the fine grains with equiaxed shape means the occurrence of dynamic 

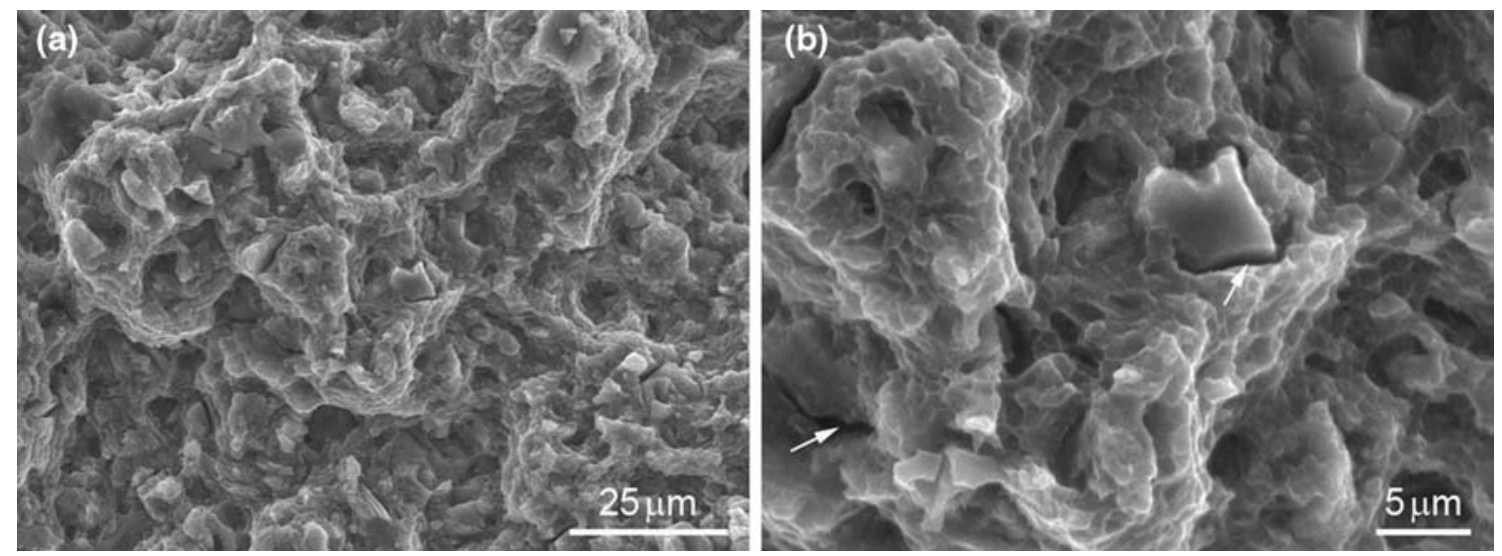

Fig. 10 Fracture surfaces of the as-extruded SiCp-reinforced magnesium matrix composite: a lower magnification; b higher magnification

recrystallization (DRX) during hot deformation process. Thus, the two kinds of orientation relationships observed at the present investigation appeared most likely during the hot deformation process. On the previous study [29] of single $\mathrm{S}-\mathrm{SiCp}$ reinforced $\mathrm{Mg}$ matrix composite, it was found that the $(01 \overline{11})$ of $\mathrm{Mg}$ parallelled to (11) of S-SiCp, and the S-SiC particles had obvious effect on promoting DRX nucleation. Based on the above observation and analysis, it could be concluded that the S-SiCp may provide nucleation site for $\mathrm{Mg}$ during hot deformation process, and the DRXed grains may nucleate preferentially at these particles.

\subsection{Interface after Fracture}

Fracture surface of the as-extruded SiCp-reinforced magnesium matrix composite is shown in Fig. 10. Many dimples can be seen clearly in Fig. 10a, which indicate ductile fracture of the matrix. Besides, the interface debonding between $\mathrm{M}-\mathrm{SiCp}$ and $\mathrm{Mg}$ indicated by white arrows in Fig. 10b also exists. This result consists with the authors' previous investigation in bimodal size SiCp-reinforced magnesium matrix composite [30]. The microcracks mainly exist near closely spaced $\mathrm{M}-\mathrm{SiCp}$, and there are no microcracks around $\mathrm{S}-\mathrm{SiCp}$ after tension at room temperature.

By using the analogy of plane strain compression of a block between two elastic platens and applying the standard force balance with sticking friction at the interface, it can be concluded that the stress at larger size particles is larger than that at fine particles at the condition of same interspacing [31]. Therefore, as compared with S-SiCp, the $\mathrm{M}-\mathrm{SiCp}$ would bear much higher stress during the deformation process. Once the stress at the interface between $\mathrm{SiCp}$ and $\mathrm{Mg}$ is larger than interfacial bonding strength, the microcracks may occur at the interface. At last, the connection of microcracks leads to the fracture of composite.

\section{Conclusions}

(1) Both $\mathrm{S}-\mathrm{SiCp}$ and $\mathrm{M}-\mathrm{SiCp}$ were relatively uniformly distributed in the $\mathrm{Mg}$ matrix, and the interfaces between $\mathrm{SiCp}$ and $\mathrm{Mg}$ matrix were very well as observed by SEM observation.

(2) Three kinds of interfaces were found between $\mathrm{M}-\mathrm{SiCp}$ and $\mathrm{Mg}$ matrix by TEM observation: clean interface, interface with the precipitated $\mathrm{Mg}_{17} \mathrm{Al}_{12}$, and the interface with the dispersedly distributed nano- $\mathrm{MgO}$ particles.

(3) The interface between S-SiCp and Mg matrix was very clean, and no IRPs were found in the present study. Besides, two kinds of specific orientation relationships at the interface between $\mathrm{S}-\mathrm{SiCp}$ and $\mathrm{Mg}$ matrix were found by HREM observation.

(4) As compared with S-SiCp, the M-SiCp would bear much higher stress, which results in the appearance of microcracks around $\mathrm{M}$-SiC particles after tension.

Acknowledgments This work was financially supported by the National Natural Science Foundation of China (Nos. 51201112, 51101043, and 51174143) and the Natural Science Foundation of Shanxi province (No. 2013021013-3).

\section{References}

[1] M.Y. Zheng, K. Wu, M. Liang, S. Kamado, Y. Kojima, Mater. Sci. Eng. A 372, 66 (2004)

[2] X.J. Wang, X.S. Hu, Y.Q. Wang, K.B. Nie, K. Wu, M.Y. Zheng, Mater. Sci. Eng. A 559, 139 (2013)

[3] C.P. Wang, H.S. Mei, R.Q. Li, D.F. Li, L. Wang, J. Liu, Z.H. Hua, L.J. Zhao, F.F. Pen, H. Li, Acta Metall. Sin. (Engl. Lett.) 26, 149 (2013)

[4] M.Y. Zhan, C.M. Li, W.W. Zhang, D.T. Zhang, Acta Metall. Sin. (Engl. Lett.) 25, 65 (2012)

[5] W.G. Wang, B.L. Xiao, Z.Y. Ma, Comp. Sci. Technol. 72, 152 (2012) 
[6] B. Hu, L.M. Peng, B.R. Powell, M.P. Balough, R.C. Kubic, A.K. Sachdev, J. Alloys Compd. 504, 527 (2010)

[7] S.H. Chen, P.P. Jin, G. Schumacher, N. Wanderk, Comp. Sci. Technol. 70, 123 (2010)

[8] Q.Q. Zhang, G.Q. Wu, Z. Huang, Y. Tao, Mater. Charact. 89, 1 (2014)

[9] K.N. Braszczýnska, L. Litýnska, A. Zyska, W. Baliga, Mater. Chem. Phys. 81, 326 (2003)

[10] B.W. Xiong, Z.F. Xu, Q.S. Yan, B.P. Lu, C.C. Cai, J. Alloys Compd. 509, 1187 (2011)

[11] K. Wu, K.K. Deng, H. Chang, Y.W. Wu, X.S. Hu, M.Y. Zheng, Acta Metall. Sin. (Engl. Lett.) 23, 99 (2010)

[12] K.K. Deng, K. Wu, X.J. Wang, Y.W. Wu, X.S. Hu, M.Y. Zheng, W.M. Gan, H.G. Brokmeier, Mater. Sci. Eng. A 527, 1630 (2010)

[13] X.J. Wang, K.B. Nie, X.S. Hu, Y.Q. Wang, X.J. Sa, K. Wu, J. Alloys Compd. 532, 78 (2012)

[14] X.J. Wang, X.S. Hu, K. Wu, M.Y. Zheng, L. Zheng, Q.J. Zhai, J. Mater. Sci. 44, 2759 (2009)

[15] M. Habibnejad-Korayem, R. Mahmudi, W.J. Poole, Mater. Sci. Eng., A 519, 198 (2009)

[16] K.K. Deng, J.Y. Shi, C.J. Wang, X.J. Wang, Y.W. Wu, K.B. Nie, K. Wu, Compos. A 43, 1280 (2012)

[17] M. Pozuelo, W.H. Kao, J.M. Yang, Mater. Charact. 77, 81 (2013)
[18] K.U. Kainer, Mater. Sci. Eng. A 135, 243 (1991)

[19] C.A. Handwerker, J.W. Cahn, J.R. Manning, Mater. Sci. Eng. A 126, 173 (1990)

[20] D.J. Lloyd, Comp. Sci. Technol. 35, 159 (1989)

[21] A. Luo, Scr. Metall. Mater. 31, 1253 (1994)

[22] V. Laurent, P. Jarry, G. Regazzoni, D. Apelian, J. Mater. Sci. 27, 4447 (1992)

[23] Y. Cai, M.J. Tan, G.J. Shen, H.Q. Su, Mater. Sci. Eng. A 282, $232(2000)$

[24] K.K. Deng, C.J. Wang, X.J. Wang, K. Wu, M.Y. Zheng, Mater. Des. 38, 110 (2012)

[25] K.K. Deng, Dissertation, Harbin Institute of Technology, 2008

[26] M.Y. Zheng, K. Wu, S. Kamado, Y. Kojima, Mater. Sci. Eng. A 348, 67 (2003)

[27] M.Y. Zheng, K. Wu, C.K. Yao, Mater. Lett. 47, 118 (2001)

[28] M.Y. Zheng, K. Wu, C.K. Yao, T. Sato, H. Tezuka, A. Kamio, D.X. Li, Mater. Lett. 41, 57 (1999)

[29] K.K. Deng, X.J. Wang, M.Y. Zheng, K. Wu, Mater. Sci. Eng. A 560, 824 (2013)

[30] K.K. Deng, X.J. Wang, C.J. Wang, J.Y. Shi, X.S. Hu, K. Wu, Mater. Sci. Eng. A 553, 74 (2012)

[31] D.J. Lloyd, Acta Metall. 39, 59 (1991) 